\title{
CA916798 gene expression is associated with multidrug resistance and predicts progression-free survival in patients with lung cancer
}

\author{
HAILING DUAN, ZAIXING YANG, LAN LIANG and XIANGDONG ZHOU \\ Department of Respiratory Disease, Southwest Hospital, Army Medical University \\ (Third Military Medical University), Chongqing 400038, P.R. China
}

Received November 7, 2018; Accepted May 3, 2019

DOI: $10.3892 / \mathrm{ol} .2019 .10436$

\begin{abstract}
CA916798 has been identified as a novel multidrug resistance gene in lung cancer cells. However, the expression patterns of CA916798 in tumor tissues prior and subsequent to chemotherapy remain unclear. In the present study, CA916798 expression levels in tumor tissues prior and subsequent to chemotherapy were detected by reverse transcription-quantitative polymerase chain reaction and immunohistochemistry analysis. The prognostic significance of CA916798 expression in tumor tissues was explored by Kaplan-Meier survival analysis and Cox proportional hazards regression analysis. The messenger RNA (mRNA) and protein expression levels of CA916798 in tumor tissues were downregulated post-chemotherapy in chemotherapy-sensitive patients with lung cancer, but not in chemotherapy-resistant patients. Downregulation of CA916798 mRNA and protein expression post-chemotherapy was significantly associated with improved progression-free survival time. The findings from the present study suggest that platinum-based chemotherapy may induce the expression of CA916798, and CA916798 may be a promising biomarker to predict chemotherapy resistance and improve therapies for patients with lung cancer.
\end{abstract}

\section{Introduction}

Lung cancer is one of the most common human malignancies in China and worldwide $(1,2)$. The 5 -year overall survival rate for lung cancer is $<20 \%$, which is largely due to late diagnosis (3). Patients with lung cancer are often diagnosed at advanced stages, when treatment options are limited (4). Platinum-based chemotherapy is recommended for patients with metastatic disease, and the administration of concurrent

Correspondence to: Dr Xiangdong Zhou, Department of Respiratory Disease, Southwest Hospital, Army Medical University (Third Military Medical University), 30 Gaotanyan Street, Chongqing 400038, P.R. China

E-mail: xiangdongzhou@126.com

Key words: CA916798, multidrug resistance, progression-free survival, lung cancer chemotherapy and radiation is beneficial for advanced lung cancer (5). Cisplatin and carboplatin are widely used first-line clinical therapeutic drugs (6). However, lung cancer cells become resistant to these drugs, which prevents an effective therapeutic response (7). Thus, the identification of novel biomarkers to predict multidrug resistance and serve as therapeutic targets may provide alternative strategies to improve the survival of patients with advanced lung cancer.

It has been reported that several genes are involved in multidrug resistance to chemotherapy in patients with lung cancer (8). Among these, members of the multidrug resistance protein (MRP) family, including MRP1, MRP2 and MRP3, are highly expressed and associated with chemotherapy resistance in lung cancer (9). Similarly, increased expression levels of P-glycoprotein (P-gp), which is encoded by the human multidrug resistant 1 (MDR1) gene, are associated with resistance to vinca alkaloids (10), etoposide (11), and taxanes (12) in patients with lung cancer. CA916798 has been identified as a novel multidrug resistance gene in cis-dichlorodiamine platinum (CDDP)-resistant lung adenocarcinoma cells (13). Overexpression of CA916798 in lung cancer cells enhances resistance to multiple chemotherapeutic agents by regulating CDDP-induced cell growth and apoptosis (14). Mechanistically, CA916798 may exert its multidrug resistance functions via the phosphoinositide 3 -kinase/AKT signaling pathway $(15,16)$. However, the majority of previous studies have focused on the molecular characteristics, biological functions and molecular mechanism of CA916798 in lung cancer (14-18). It is still unknown whether CA916798 expression is associated with platinum-based chemotherapy in tumor tissues from patients with lung cancer.

The present study evaluated the messenger RNA (mRNA) and protein expression levels of CA916798 in tumor tissues prior and subsequent to chemotherapy in patients with advanced lung cancer. Both the mRNA and protein expression levels of CA916798 were altered in chemotherapy-sensitive lung cancer tissues. The present study further evaluated the prognostic implications of CA916798 mRNA and protein expression levels in patients with lung cancer.

\section{Materials and methods}

Patients and tissue samples. Patients newly diagnosed with lung cancer at the Southwest Hospital of the Third Military 
Medical University (Chongqing, China) were enrolled between March and December 2016. Tissue specimens were collected prior to chemotherapy and following 2 cycles (with each cycle repeated every 3 weeks) of chemotherapy by bronchoscopy. The patients were under conscious sedation and intubated with a flexible bronchoscope (Olympus Corporation). A transbronchial lung biopsy was performed under fluoroscopic guidance. The bronchopulmonary segment for obtaining specimens was determined prior to the procedure based on computed tomography (CT) of the chest. The demographic characteristics of the patients, including age, sex and smoking status, were collected through a questionnaire. The clinicopathological characteristics of the patients, including pathological stage (TNM staging system) (19), maximum tumor diameter and histological type, were collected through hospital examinations, including CT and pathological examination. The inclusion criteria were: i) Patients who were diagnosed by histology or cytology as exhibiting lung cancer, including lung squamous cell carcinoma, lung adenocarcinoma and small cell lung cancer; ii) patients with advanced lung cancer, including stage III and IV lung cancer; iii) patients who had never received any radiation or chemotherapy; iv) patients who had received $\geq 2$ cycles of first-line chemotherapy; and v) patients who were able to comply with the study and follow-up. The exclusion criteria were: i) Patients who had received surgery; ii) patients who refused treatment; and iii) patients who had been diagnosed with other malignancies. According to the inclusion and exclusion criteria, 30 patients were included in the study. Written informed consent was obtained from all the patients. The research protocol was approved by the Ethics Committee of the Third Military Medical University.

Reverse transcription-quantitative polymerase chain reaction $(R T-q P C R)$ analysis. Total RNA was isolated from tumor tissues using TRIzol ${ }^{\circledR}$ reagent (Takara Biotechnology Co., Ltd.) according to the manufacturer's instructions. The concentration and purity of the RNA samples were evaluated by an ultraviolet spectrophotometer (Thermo Fisher Scientific, Inc.). The integrity of the RNA samples was determined by agarose gel electrophoresis. Upon quantification, $1 \mu \mathrm{g}$ total RNA was reverse transcribed into complementary DNA using PrimeScript ${ }^{\mathrm{TM}}$ RT reagent kit with gDNA eraser (Takara Biotechnology Co., Ltd.). The temperature protocol for the RT-PCR was as follows: $37^{\circ} \mathrm{C}$ for $15 \mathrm{~min}$, followed by $85^{\circ} \mathrm{C}$ for 5 sec. qPCR was conducted using SYBR Premix Ex Taq (Takara Biotechnology Co., Ltd.) in a CFX 96 thermal cycler (Bio-Rad Laboratories, Inc.). The thermocycling conditions for the qPCR was as follows: $95^{\circ} \mathrm{C}$ for $30 \mathrm{sec}$, followed by 40 cycles of $95^{\circ} \mathrm{C}$ for $5 \mathrm{sec}, 60^{\circ} \mathrm{C}$ for $30 \mathrm{sec}$ and $72^{\circ} \mathrm{C}$ for $30 \mathrm{sec}$, followed by a final step of $72^{\circ} \mathrm{C}$ for $2 \mathrm{~min}$. The expression levels of GAPDH were used as the internal control. Quantification cycle $(\mathrm{Cq})$ values of GAPDH mRNA $<25$ and $\mathrm{Cq}$ values of CA916798 mRNA $<35$ were considered of good quality. The $2^{-\Delta \Delta C q}$ method (20) was used to calculate the relative expression of CA916798 as follows: $\Delta \mathrm{Cq}=\mathrm{Cq}_{(\mathrm{CA} A 16798)}{ }^{-} \mathrm{Cq}_{(\mathrm{GAPDH})}$, where $\Delta \Delta \mathrm{Cq}=\Delta \mathrm{Cq}_{\text {(post-chemotherapy) }}{ }^{-}$ $\Delta \mathrm{Cq}_{\text {(pre-chemotherapy) }}$ and fold-change $=2^{-\Delta \Delta \mathrm{Cq}}$. The primers used in RT-qPCR analysis were synthesized by Sangon Biotech Co., Ltd., and the sequences are as follows: CA916798 forward, 5'-GCTTCCTCCTCAACCTCGTCCT-3' and reverse, 5'-GTA
GCCCACTTATCCACCTTCTCC-3'; and GAPDH forward, 5'-AAGGTGAAGGTCGGAGTCAAC-3' and reverse, 5'-GGG GTCATTGATGGCAACAATA-3'.

Immunohistochemistry (IHC) analysis. Tumor tissues were obtained by bronchoscopy, fixed in $10 \%$ buffered formalin for 24 to $48 \mathrm{~h}$ at room temperature, paraffin embedded and sectioned at a thickness of $4 \mu \mathrm{m}$. The paraffin-embedded lung cancer tissue sections were deparaffinized in xylene, rehydrated through graded alcohol $(95,80$ and $70 \%)$ to water and immersed in citrate buffer ( $\mathrm{pH}$ 6.0). Antigen retrieval was accomplished using $0.05 \mathrm{M}$ glycine- $\mathrm{HCl}$ buffer ( $\mathrm{pH} 3.5$ ) containing $0.01 \%$ EDTA at $95^{\circ} \mathrm{C}$ for $15 \mathrm{~min}$. The sections were blocked with 5\% BSA (Boster Biological Technology) and $0.1 \%$ Triton in PBS for $30 \mathrm{~min}$ at $37^{\circ} \mathrm{C}$. The sections were then incubated overnight at $4^{\circ} \mathrm{C}$ in citrate buffer with anti-CA916798 antibody (1:200). The anti-CA916798 polyclonal antibody was produced and gifted by Dr Haijing Wang at the Army Military Medical University (Chongqing, China) (14). The sections were then incubated with horseradish peroxidase-conjugated secondary antibody $(1: 1,000$; cat. no. ab6721; Abcam) for $30 \mathrm{~min}$ at room temperature. A section incubated with PBS instead of primary anti-CA916798 antibody was used as a negative control. The positive control was a positive biopsy from our previous study (18). Immunostaining was evaluated by 2 pathologists blinded to the results. The immunohistochemical images were obtained at x200 magnification under an optical microscope (Olympus Corporation). For each section, 5 visual fields were randomly selected to calculate the percentage of CA916798-positive cells. The intensity of CA916798 protein expression was scored and divided into 4 levels according to the percentage of CA916798-positive cells: 0 (negative staining) for $0-10 \% ; 1$ (weak positive staining) for $10-25 \%$; 2 (moderate positive staining) for $25-75 \%$; and 3 (strong positive staining) for $75-100 \%$. A score of 0 was defined as negative and a score of 1-3 was defined as positive.

Patient follow-up and therapeutic evaluation. All patients were treated with first-line platinum-based chemotherapy on day 1 , and repeated every 3 weeks (120 mg cisplatin, $45 \mathrm{mg}$ lobaplatin or $140 \mathrm{mg}$ nedaplatin in combination with $1,800 \mathrm{mg}$ gemcitabine, $120 \mathrm{mg}$ docetaxel, $240 \mathrm{mg}$ irinotecan or $240 \mathrm{mg}$ paclitaxel liposome). Subsequently, CT imaging was conducted to evaluate the response to chemotherapy following 2 cycles of therapy. Response Evaluation Criteria in Solid Tumors version 1.1 (21) was used to classify patients into complete response (CR), partial response (PR), stable disease (SD) and progressive disease (PD) groups. Patients were considered to be responsive to chemotherapy when they exhibited a CR or PR. Patients who had SD or PD were classified as non-responsive. Progression-free survival time was defined from the first day of chemotherapy to disease progression, tumor-induced mortality or last follow-up. All patients were actively followed up within 6 months of diagnosis, with subsequent annual follow-ups by telephone interview or outpatient visit.

Statistical analysis. Statistical analyses were conducted using SPSS 22.0 software (IBM Corp.) and graphs were generated with GraphPad Prism 5.0 (GraphPad Software, Inc.). Continuous variables were compared with either unpaired or 
Table I. Demographic and clinical characteristics of chemotherapy-sensitive $(n=19)$ and -resistant ( $n=11)$ lung cancer patients in the present study.

Response to chemotherapy

\begin{tabular}{|c|c|c|c|c|}
\hline $\begin{array}{l}\text { Patient } \\
\text { characteristics }\end{array}$ & $\mathrm{n}(\%)$ & $\begin{array}{c}\text { Chemotherapy-sensitive, } \\
\text { CR + PR }\end{array}$ & $\begin{array}{c}\text { Chemotherapy-resistant, } \\
\text { SD + PD }\end{array}$ & P-value \\
\hline Total patients & $30(100.00)$ & & & \\
\hline Age at diagnosis, years ${ }^{\mathrm{a}}$ & & $58.26 \pm 9.37$ & $60.73 \pm 5.82$ & $0.703^{b}$ \\
\hline \multicolumn{5}{|l|}{ Sex, n $(\%)$} \\
\hline Male & $25(83.33)$ & $15(78.95)$ & $10(90.91)$ & $0.626^{c}$ \\
\hline Female & $5(16.67)$ & $4(21.05)$ & $1 \quad(9.09)$ & \\
\hline \multicolumn{5}{|l|}{ Histological type, n (\%) } \\
\hline NSCLC & $20(66.67)$ & $10(52.63)$ & $10(90.91)$ & $0.049^{c}$ \\
\hline SCLC & $10(33.33)$ & $9(47.37)$ & 1 (9.09) & \\
\hline \multicolumn{5}{|l|}{ Pathological stage, n (\%) } \\
\hline III & $17(56.67)$ & $9(47.37)$ & $8(72.73)$ & $0.259^{c}$ \\
\hline IV & $13(43.33)$ & $10(52.63)$ & $3(27.27)$ & \\
\hline \multicolumn{5}{|l|}{ Smoking status, n (\%) } \\
\hline Smoker & $24(80.00)$ & $14(73.68)$ & $10(90.91)$ & $0.372^{\mathrm{c}}$ \\
\hline Never & $6(20.00)$ & $5(26.32)$ & 1 (9.09) & \\
\hline Maximum tumor diameter ${ }^{a}$ & & $65.52 \pm 20.28$ & $77.93 \pm 27.52$ & $0.553^{\mathrm{b}}$ \\
\hline
\end{tabular}

${ }^{a}$ Mean \pm standard deviation. ${ }^{b}$ Student's t-test. ${ }^{~}$ Fisher's exact test. CR, complete response; PR, partial response; SD, stable disease; PD, progressive disease; NSCLC, non-small cell lung cancer.

paired Student's t-test. Fisher's exact test was used to assess the differences in proportions between 2 groups. Progression-free survival was analyzed by the Kaplan-Meier method with upregulated and downregulated expression of CA916798. A multivariate Cox proportional hazards regression analysis was used to explore the prognostic significance of CA916798 expression. Two-sided $\mathrm{P}<0.05$ was considered to indicate a statistically significant difference.

\section{Results}

Demographic and clinicopathological characteristics. A total of 30 patients were included in the present study, of which $83.3 \%(25 / 30)$ were male, with an overall mean age of $59.17 \pm 8.22$ years. In total, $66.7 \%(20 / 30)$ of patients had non-small cell lung cancer. According to the American Joint Committee on Cancer Tumor-Node-Metastasis staging system (19), 56.7\% (17/30) of patients had stage III cancer and $43.3 \%$ (13/30) had stage IV cancer. The mean maximum tumor diameter was $70.06 \pm 23.52 \mathrm{~mm}$ (Table I). All patients received platinum-based chemotherapy for 2 cycles. A total of 19 patients who achieved CR or PR were assigned to the chemotherapy-sensitive group, while 11 patients who had SD or PD were assigned to the chemotherapy-resistant group according to CT manifestations (Fig. S1). As shown in Table I, response to chemotherapy was not associated with age, sex, pathological stage, smoking status or maximum tumor diameter, while the association between drug resistance and histological type was significant $(\mathrm{P}=0.049)$.
CA916798 mRNA expression is downregulated post-chemotherapy in chemotherapy-sensitive patients with lung cancer. Tumor samples were collected from 30 patients prior to chemotherapy and following 2 cycles of chemotherapy. Subsequently, the dynamic changes in CA916798 mRNA expression levels were investigated in the 30 paired lung cancer tissues using RT-qPCR. CA916798 mRNA expression levels were significantly downregulated in post-chemotherapy tumor tissues compared with those in pre-chemotherapy tissues in chemotherapy-sensitive patients $(\mathrm{P}<0.05)$ (Fig. 1A). However, CA916798 mRNA expression levels did not significantly change in chemotherapy-resistant lung cancer samples (P>0.05) (Fig. 1B). The fold-change in CA916798 mRNA levels following chemotherapy, normalized to GAPDH and relative to the expression levels prior to chemotherapy, was calculated for each patient. The fold-change in CA916798 mRNA expression levels in the chemotherapy-sensitive lung cancer group of patients was significantly lower compared with those in the chemotherapy-resistant group $(\mathrm{P}<0.05)$ (Fig. 1C).

CA916798 protein expression is downregulated following chemotherapy in chemotherapy-sensitive patients with lung cancer. To identify the protein expression levels of CA916798 in lung cancer tissues, IHC staining of tumor specimens was used to analyze the protein expression levels of CA916798. CA916798 protein was positively detected in nearly all biopsy specimens from the patients with lung cancer prior to chemotherapy. However, the IHC staining after 2 cycles of chemotherapy showed that CA916798 protein was only 
A

Chemotherapy-sensitive group

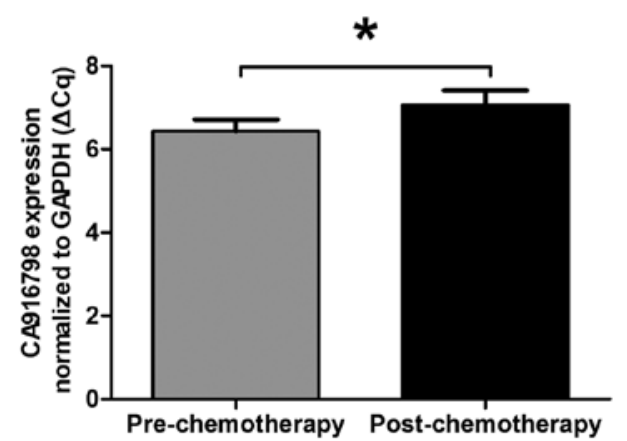

C

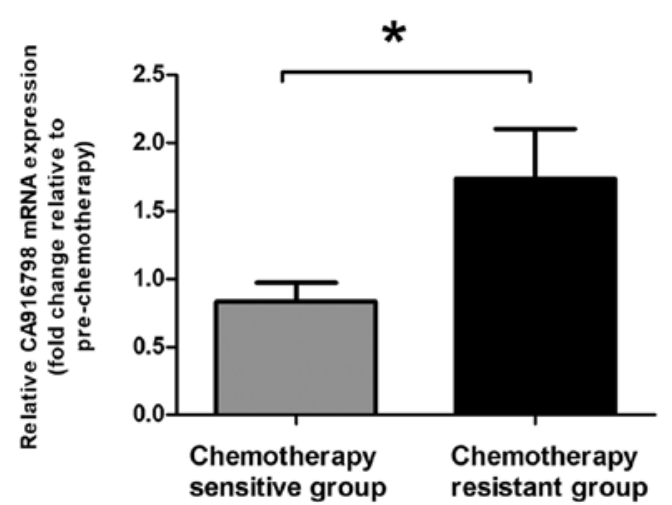

B

\section{Chemotherapy-resistant group}

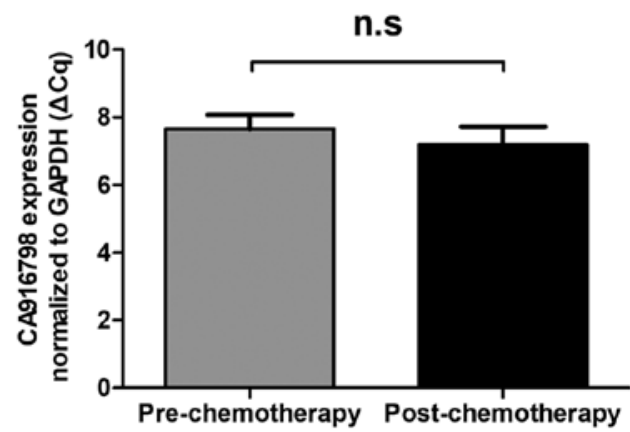

Figure 1. CA916798 mRNA expression levels prior and subsequent to 2 cycles of chemotherapy in lung cancer tissues. (A) CA916798 mRNA expression levels prior and subsequent to 2 cycles of chemotherapy in the chemotherapy-sensitive group. $\triangle \mathrm{Cq}$ was used to show the expression level of CA916798 mRNA $(\Delta \mathrm{Cq}=\mathrm{CqCA} 916798-\mathrm{CqGAPDH})$. Lower $\Delta \mathrm{Cq}$ values indicate higher expression. "P $<0.05$ pre-chemotherapy vs. post-chemotherapy using paired Student's t-test. (B) CA916798 mRNA expression levels prior and subsequent to 2 cycles of chemotherapy in the chemotherapy-resistant group. $\Delta$ Cq was used to show the expression level of CA916798 mRNA ( $\Delta$ Cq=CqCA916798-CqGAPDH). Lower $\Delta$ Cq values indicate higher expression. No significant difference between pre-chemotherapy and post-chemotherapy using paired Student's t-test. (C) Relative CA916798 mRNA expression in lung cancer tissues post-chemotherapy compared with that pre-chemotherapy. "P<0.05 chemotherapy-sensitive group vs. chemotherapy-resistant group using Student's t-test. mRNA, messenger RNA; Cq, quantification cycle; n.s, not significant.

positively stained in $42.1 \%$ (8/19) of samples from chemotherapy-sensitive patients, which was significantly lower than the percentage exhibited by chemotherapy-resistant patients $(\mathrm{P}<0.05)$ (Table II). The positive staining of CA916798 protein was also compared before and after chemotherapy. In chemotherapy-sensitive patients, the expression of CA916798 was significantly decreased post-chemotherapy in $89.5 \%$ (17/19) of lung cancer cases compared with that in chemotherapy-resistant patients $(\mathrm{P}<0.05)$ (Table II). Representative IHC staining results of CA916798 are shown in Fig. S2.

Expression of CA916798 is associated with progression-free survival in patients with lung cancer. Since CA916798 expression levels were associated with the response to chemotherapy, the present study further explored the prognostic significance of CA916798 expression in lung cancer. Kaplan-Meier survival analysis was performed to explore the association between CA916798 mRNA expression and progression-free survival time of the patients. The patients were divided into two groups: A CA916798 mRNA downregulated group, which included patients with downregulated expression of CA916798 mRNA post-chemotherapy and a CA916798 mRNA upregulated group, which included patients with upregulated expression of CA916798 mRNA post-chemotherapy. The downregulated expression of CA916798 mRNA post-chemotherapy was significantly associated with improved progression-free survival time $(\mathrm{P}=0.009)$ (Fig. $2 \mathrm{~A})$. The association with progression-free survival time in patients with lung cancer remained significant in multivariate Cox proportional-hazards regression analysis upon adjusting for age, sex, histological type, pathological stage, smoking status and maximum tumor diameter $[\mathrm{n}=30$; hazard ratio (HR), $0.304 ; 95 \%$ confidence interval (CI), 0.114-0.807; $\mathrm{P}=0.017]$. Consistent with the results of CA916798 mRNA expression, Kaplan-Meier analysis also indicated that downregulated protein expression of CA916798 post-chemotherapy was significantly associated with improved progression-free survival time $(\mathrm{P}<0.001)$ (Fig. 2B). Upon adjusting for age, gender, histological type, pathological stage, smoking status and maximum tumor diameter, the Cox proportional hazard model indicated that downregulated protein expression of CA916798 was an independent prognostic factor for lung cancer $(\mathrm{n}=30 ; \mathrm{HR}, 0.145$; 95\% CI, 0.050-0.418; $\mathrm{P}<0.001)$.

Changes in CA91679 expression are associated with response to continued chemotherapy in patients with lung cancer 
Table II. Associations between CA916798 protein expression level and chemotherapy response in chemotherapy-sensitive $(\mathrm{n}=19)$ and -resistant $(\mathrm{n}=11)$ lung cancer patients in the present study.

\begin{tabular}{|c|c|c|c|}
\hline \multirow[b]{2}{*}{ CA916798 protein level } & \multicolumn{2}{|c|}{ Response to chemotherapy } & \multirow[b]{2}{*}{ P-value } \\
\hline & $\begin{array}{c}\text { Chemotherapy-sensitive, } \\
\text { CR + PR, } \mathrm{n}(\%)\end{array}$ & $\begin{array}{c}\text { Chemotherapy-resistant, } \\
\text { SD + PD, n (\%) }\end{array}$ & \\
\hline CA916798 protein level pre-chemotherapy & & & $>0.05^{\mathrm{a}}$ \\
\hline Positive $(\mathrm{n}=28)$ & $18(94.74)$ & $10(90.91)$ & \\
\hline Negative $(n=2)$ & $1(5.26)$ & $1(9.09)$ & \\
\hline CA916798 protein level post-chemotherapy & & & $0.002^{\mathrm{a}}$ \\
\hline Positive $(n=19)$ & $8(42.11)$ & $11(100.00)$ & \\
\hline Negative $(n=11)$ & $11(57.89)$ & $0(0.00)$ & \\
\hline Changes of CA916798 protein post-chemotherapy & & & $<0.001^{\mathrm{a}}$ \\
\hline Downregulated $(\mathrm{n}=18)$ & $17(89.47)$ & $1(9.09)$ & \\
\hline Upregulated $(\mathrm{n}=8)$ & $0(0.00)$ & $8(72.73)$ & \\
\hline Unchanged $(n=4)$ & $2(10.53)$ & $2(18.18)$ & \\
\hline
\end{tabular}

${ }^{a}$ Fisher's exact test. CR, complete response; PR, partial response; SD, stable disease PD, progressive disease.

A

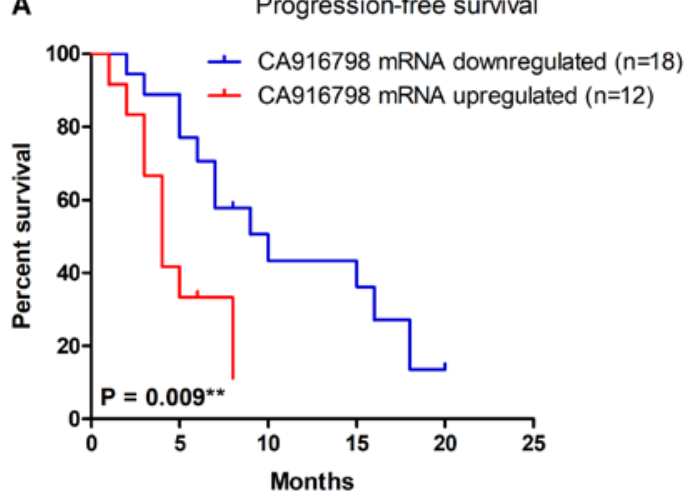

B

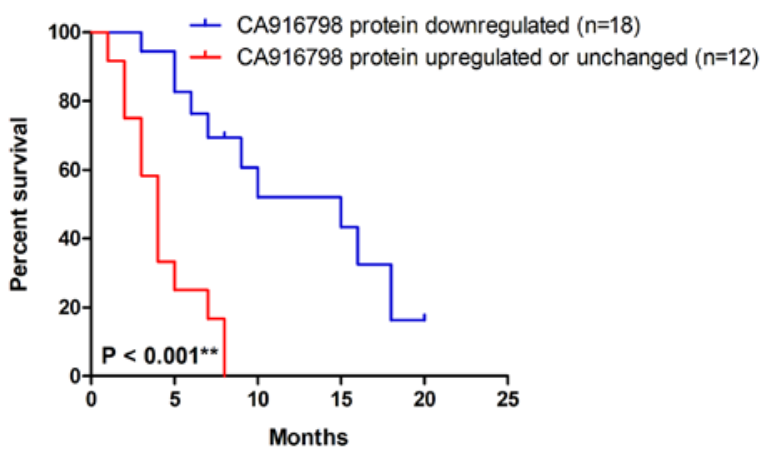

Figure 2. Kaplan-Meier curves for progression-free survival of patients with lung cancer based on the change in CA916798 expression levels. (A) Kaplan-Meier curves for progression-free survival time of patients with lung cancer with upregulated and downregulated CA916798 messenger RNA expression. ${ }^{* *} \mathrm{P}<0.001$ by log-rank test. (B) Kaplan-Meier curves for progression-free survival time of patients with lung cancer with upregulated and downregulated CA916798 protein expression. ${ }^{* *} \mathrm{P}<0.001$ by log-rank test.

and SD. Following 2 cycles of chemotherapy, 11 patients with lung cancer were resistant to chemotherapy. These SD patients continued treatment with first-line platinum-based chemotherapy. Of these, only 3 patients exhibited response to continued chemotherapy, which was associated with changes in CA91679 protein expression (Table III). In the SD patients who were resistant to continued chemotherapy, $100 \%(8 / 8)$ of the patients displayed upregulation of CA916798 protein expression following 2 cycles of chemotherapy, which was significantly higher than the percentage exhibited by chemotherapy-sensitive patients $(\mathrm{P}=0.005)$ (Table III).

\section{Discussion}

The present study demonstrated that CA916798, a novel multidrug resistance gene, was downregulated following 2 cycles of chemotherapy in chemotherapy-sensitive patients with lung cancer. In addition, CA916798 expression level was demonstrated to be an independent predictor for progression-free survival time in patients with advanced lung cancer.

Primary therapeutic strategies for lung cancer include surgical treatment, radiation therapy, targeted therapy, immunotherapy and chemotherapy $(22,23)$. For early-stage lung cancer, surgery is the major treatment modality to improve both overall survival time and progression-free survival time (24). However, based on the preponderance of advanced-stage diagnoses, chemotherapy is still used for the treatment of lung cancer $(25,26)$. For patients receiving chemotherapy, multidrug resistance limits the ability to treat advanced lung cancer effectively (27). Multidrug resistance is a phenomenon that allows cancer cells to become resistant to multiple structurally and mechanistically distinct anticancer drugs (28). Multidrug resistance, existing prior to chemotherapy or appearing upon exposure to anticancer drug treatment, can be attributed to different mechanisms $(29,30)$. The most studied mechanism of multidrug resistance is drug efflux, which is caused by ATP-binding cassette transporters (31). P-glycoprotein 1 or MDR1 and MRP2 are typical efflux transmembrane proteins that are involved in multidrug resistance in various types of 
Table III. Associations between CA916798 protein expression level and response to continued chemotherapy in chemotherapy-sensitive $(n=3)$ and -resistant $(n=8)$ patients with stable lung cancer.

Response to continued chemotherapy

Chemotherapy-sensitive,

$\mathrm{n}(\%)$
Chemotherapy-resistant, $\mathrm{n}(\%)$

P-value

CA916798 protein level

$0 \quad(0.00)$

$1(33.33)$

$2(66.67)$

0.005

Changes in CA916798 protein post-chemotherapy

Upregulated $(\mathrm{n}=8)$

Downregulated $(\mathrm{n}=1)$

Unchanged $(n=2)$
$8(100.00)$

$0 \quad(0.00)$

$0 \quad(0.00)$ cancers $(32,33)$. However, these genes are not fully responsible for the mechanism of multidrug resistance, and the clinical evidence is inconclusive with regard to an association between these genes and outcomes in lung cancer (34). Thus, a better understanding of novel molecular determinants of multidrug resistance is important. Establishment of novel predictive and prognostic biomarkers of multidrug resistance is one of the most important strategies to overcome chemotherapy resistance in lung cancer.

In our previous studies, CA916798 was identified as a novel gene in a multidrug resistant cell line by suppression subtractive hybridization (13). Gain- and loss-of-function of CA916798 in lung cancer cell lines were investigated, which revealed that CA916798 could enhance cell resistance to chemotherapeutic agents $(14,15)$. However, the clinical value of CA916798 expression remained uncertain. In the present study, following 2 cycles of standard chemotherapy, 63.3\% (19 out of 30) of patients responded to drug treatments effectively. Dynamic changes in CA916798 mRNA and protein expression levels were observed in tumor tissues following 2 cycles of standard chemotherapy. In the chemotherapy-sensitive patients, both the CA916798 mRNA and protein expression levels were downregulated following 2 cycles of chemotherapy. However, the CA916798 mRNA and protein expression levels were upregulated following chemotherapy in chemotherapy-resistant patients. A previous study also reported that the expression of MRP1 was significantly upregulated following treatment with platinum-based combinations in lung cancer (35). Similarly, increased MDR1 mRNA and protein expression levels have been associated with chemotherapy $(36,37)$. These studies, alongside those on CA916798, suggest that platinum-based chemotherapy may induce the expression of multidrug resistance genes.

The present study has elucidated how CA916798 expression level changed following 2 cycles of platinum-based chemotherapy. Thus, the expression of CA916798 may be a predictive and prognostic biomarker for chemotherapy sensitivity in patients with advanced lung cancer. The present study further explored the prognostic significance of CA916798 expression. Downregulated CA916798 mRNA and protein expression levels were associated with improved progression-free survival in lung cancer. Thus, if CA916798 expression in tumor tissue is downregulated following 2 cycles of chemotherapy, the patient will have an improved prognosis. Conversely, if CA916798 expression is upregulated following
2 cycles of chemotherapy, the patient will have a poor prognosis. These results suggested that CA916798 expression could be a novel biomarker for predicting progression of lung cancer following platinum-based chemotherapy.

In clinical practice, it is often difficult for doctors to select between continuing chemotherapy or replacing it with other treatment options, such as radiotherapy or biological therapy, for patients with SD who had no significant reduction in lesions following 2 cycles of chemotherapy. In the present study, 11 patients who had SD following 2 cycles of chemotherapy continued treatment with platinum-based chemotherapy. Of these, 8 patients with upregulated CA916798 protein expression were resistant to continued chemotherapy. However, 3 patients with downregulated (or unchanged) CA916798 protein expression were sensitive to continued chemotherapy. The results suggested that, if CA916798 expression was upregulated following 2 cycles of chemotherapy, patients with SD may remain resistant to continued chemotherapy and the type of treatment should be changed.

Several limitations exist in the present study. Firstly, in order to explore the dynamic changes in CA916798 expression, tumor tissues should be collected from patients prior to chemotherapy and following 2 cycles of chemotherapy. Due to the strict inclusion and exclusion criteria, the sample size was limited, which may not ensure sufficient statistical power. The results require validation in further studies with larger sample size. Secondly, the histological type in the present study was complex, since it included non-small cell lung cancer (lung adenocarcinoma and lung squamous cell carcinoma) and small cell lung cancer. In the present study, small cell lung cancer may have been more sensitive to chemotherapy compared with non-small cell lung cancer. Since different histological types of lung cancer may have different sensitivities to chemotherapy (38), subgroup analysis of different histological types of lung cancer is also required.

In conclusion, the present study demonstrated that both CA916798 mRNA and protein expression levels are downregulated post-chemotherapy in chemotherapy-sensitive patients with lung cancer, but not in chemotherapy-resistant patients. Furthermore, the dynamic change in CA916798 mRNA or protein expression level post-chemotherapy is an independent prognostic factor for lung cancer. These findings suggest that CA916798 may be a promising biomarker to predict chemotherapy resistance and optimize therapy for patients with lung cancer. 


\section{Acknowledgements}

Not applicable.

\section{Funding}

The present study was supported by Wu Jieping Medical Foundation Clinical Research Funding (grant no. 320.6750.12227).

\section{Availability of data and materials}

All data generated or analyzed during the present study are included in this article.

\section{Authors' contributions}

$\mathrm{XZ}$ designed the study, interpreted the results and obtained funding. HD performed the experiments and participated in the study design, results interpretation and manuscript writing. ZY and LL collected the human tissue samples and provided valuable technical support and conceptual advice. All authors read and approved the final version of the manuscript.

\section{Ethics approval and consent to participate}

The research protocol was approved by the Ethics Committee of the Third Military Medical University (Chongqing, China). All patients provided written informed consent.

\section{Patient consent for publication}

Not applicable.

\section{Competing interests}

The authors declare that they have no competing interests.

\section{References}

1. Chen W, Zheng R, Baade PD, Zhang S, Zeng H, Bray F, Jemal A, $\mathrm{Yu}$ XQ and He J: Cancer statistics in China, 2015. CA Cancer J Clin 66: 115-132, 2016.

2. Siegel RL, Miller KD and Jemal A: Cancer statistics, 2018. CA Cancer J Clin 68: 7-30, 2018.

3. Torre LA, Siegel RL and Jemal A: Lung cancer statistics. Adv Exp Med Biol 893: 1-19, 2016.

4. Zimmermann S and Peters S: Present standards and future perspectives in the treatment of metastatic non-small cell lung cancer. Cancer Metastasis Rev 34: 173-182, 2015.

5. Azzoli CG, Giaccone G and Temin S: American society of clinical oncology clinical practice guideline update on chemotherapy for stage IV non-small-cell lung cancer. J Oncol Pract 6 . 39-43, 2010.

6. Hirsch FR, Scagliotti GV, Mulshine JL, Kwon R, Curran WJ Jr, Wu YL and Paz-Ares L: Lung cancer: Current therapies and new targeted treatments. Lancet 389: 299-311, 2017.

7. Nascimento AV, Singh A, Bousbaa H, Ferreira D, Sarmento B and Amiji MM: Overcoming cisplatin resistance in non-small cell lung cancer with Mad2 silencing siRNA delivered systemically using EGFR-targeted chitosan nanoparticles. Acta Biomater 47 71-80, 2017.

8. Nikolaou M, Pavlopoulou A, Georgakilas AG and Kyrodimos E: The challenge of drug resistance in cancer treatment: A current overview. Clin Exp Metastasis 35: 309-318, 2018.
9. Zhang Y, Yang SH and Guo XL: New insights into Vinca alkaloids resistance mechanism and circumvention in lung cancer. Biomed Pharmacother 96: 659-666, 2017.

10. Joshi P, Vishwakarma RA and Bharate SB: Natural alkaloids as $\mathrm{P}$-gp inhibitors for multidrug resistance reversal in cancer. Eur J Med Chem 138: 273-292, 2017.

11. Pesic M, Markovic JZ, Jankovic D, Kanazir S, Markovic ID, Rakic L and Ruzdijic S: Induced resistance in the human non small cell lung carcinoma (NCI-H460) cell line in vitro by anticancer drugs. J Chemother 18: 66-73, 2006.

12. Yang $\mathrm{CH}$, Wang $\mathrm{C}$, Ojima I and Horwitz SB: Taxol analogues exhibit differential effects on photoaffinity labeling of $\beta$-tubulin and the multidrug resistance associated P-glycoprotein. J Nat Prod 81: 600-606, 2018.

13. He J, Lan X, Duan HL, Luo H and Zhou XD: CA916798 affects growth and metastasis of androgen-dependent prostate cancer cells. Eur Rev Med Pharmacol Sci 22: 4477-4487, 2018.

14. Wang HJ, Yang HP, Zhou XD, Dai XT, Chen YF and Xiong W: CA916798 regulates multidrug resistance of lung cancer cells. Asian Pac J Cancer Prev 12: 3403-3408, 2011.

15. Qi Z, Wang Y and Zhou X: CA916798 gene participates in cisplatin resistance of human lung adenocarcinoma A549 cells through PI3K/AKT/mTOR pathway. Nan Fang Yi Ke Da Xue Xue Bao 32: 1290-1293, 2012 (In Chinese).

16. Wang YL, Zhu BJ, Qi ZZ, Wang HJ and Zhou XD: Akt1 enhances CA916798 expression through mTOR pathway. PLoS One 8: e62327, 2013.

17. Wang HJ, Yang ZX, Dai XT, Chen YF, Yang HP and Zhou XD: Bisdemethoxycurcumin sensitizes cisplatin-resistant lung cancer cells to chemotherapy by inhibition of CA916798 and PI3K/AKT signaling. Apoptosis 22: 1157-1168, 2017.

18. Yang X, Tang C, Luo H, Wang H and Zhou X: Shp2 confers cisplatin resistance in small cell lung cancer via an AKT-mediated increase in CA916798. Oncotarget 8: 23664-23674, 2017.

19. Travis WD, Brambilla E, Rami-Porta R, Vallières E, Tsuboi M, Rusch V and Goldstraw P; International Staging Committee: Visceral pleural invasion: Pathologic criteria and use of elastic stains: Proposal for the 7th edition of the TNM classification for lung cancer. J Thorac Oncol 3: 1384-1390, 2008.

20. Livak KJ and Schmittgen TD: Analysis of relative gene expression data using real-time quantitative PCR and the 2(-Delta Delta C(T)) method. Methods 25: 402-408, 2001.

21. Nishino M, Jackman DM, Hatabu H, Yeap BY, Cioffredi LA, Yap JT, Jänne PA, Johnson BE and Van den Abbeele AD: New response evaluation criteria in solid tumors (RECIST) guidelines for advanced non-small cell lung cancer: Comparison with original RECIST and impact on assessment of tumor response to targeted therapy. AJR Am J Roentgenol 195: W221-W228, 2010.

22. da Costa DJ, Parrish JW, Singh NK and Hsia DW: Lung cancer: Advances and insights in diagnosis, treatment, and palliation. Am J Respir Crit Care Med 198: 667-669, 2018.

23. Zappa C and Mousa SA: Non-small cell lung cancer: Current treatment and future advances. Transl Lung Cancer Res 5: 288-300, 2016

24. Yang P: Epidemiology of lung cancer prognosis: Quantity and quality of life. Methods Mol Biol 471: 469-486, 2009.

25. Spira A and Ettinger DS: Multidisciplinary management of lung cancer. N Engl J Med 350: 379-392, 2004.

26. Burdett SS, Stewart LA and Rydzewska L: Chemotherapy and surgery versus surgery alone in non-small cell lung cancer. Cochrane Database Syst Rev: CD006157, 2007.

27. Kim ES: Chemotherapy resistance in lung cancer. Adv Exp Med Biol 893: 189-209, 2016

28. Ullah MF: Cancer multidrug resistance (MDR): A major impediment to effective chemotherapy. Asian Pac J Cancer Prev 9: 1-6, 2008.

29. Zahreddine $\mathrm{H}$ and Borden KL: Mechanisms and insights into drug resistance in cancer. Front Pharmacol 4: 28, 2013.

30. Kartal-Yandim M, Adan-Gokbulut A and Baran Y: Molecular mechanisms of drug resistance and its reversal in cancer. Crit Rev Biotechnol 36: 716-726, 2016.

31. Cnubben NH, Wortelboer HM, van Zanden JJ, Rietjens IM and van Bladeren PJ: Metabolism of ATP-binding cassette drug transporter inhibitors: Complicating factor for multidrug resistance. Expert Opin Drug Metab Toxicol 1: 219-232, 2005.

32. Sodani K, Patel A, Kathawala RJ and Chen ZS: Multidrug resistance associated proteins in multidrug resistance. Chin J Cancer 31: 58-72, 2012. 
33. Choi $\mathrm{CH}$ : $\mathrm{ABC}$ transporters as multidrug resistance mechanisms and the development of chemosensitizers for their reversal. Cancer Cell Int 5: 30, 2005.

34. Leslie EM, Deeley RG and Cole SP: Multidrug resistance proteins: Role of P-glycoprotein, MRP1, MRP2, and BCRP (ABCG2) in tissue defense. Toxicol Appl Pharmacol 204: 216-237, 2005.

35. Triller N, Korosec P, Kern I, Kosnik M and Debeljak A: Multidrug resistance in small cell lung cancer: Expression of P-glycoprotein, multidrug resistance protein 1 and lung resistance protein in chemo-naive patients and in relapsed disease. Lung Cancer 54: 235-240, 2006.

36. Roy S,KennyE,Kennedy S,Larkin A,BallotJ,PerezDe VillarrealM, Crown J and O'Driscoll L: MDR1/P-glycoprotein and MRP-1 mRNA and protein expression in non-small cell lung cancer. Anticancer Res 27: 1325-1330, 2007.
37. Melguizo C, Prados J, Luque R, Ortiz R, Caba O, Alvarez PJ, Gonzalez B and Aranega A: Modulation of MDR1 and MRP3 gene expression in lung cancer cells after paclitaxel and carboplatin exposure. Int J Mol Sci 13: 16624-16635, 2012.

38. Chan BA and Coward JI: Chemotherapy advances in small-cell lung cancer. J Thorac Dis 5 (Suppl 5): S565-S578, 2013.

This work is licensed under a Creative Commons Attribution-NonCommercial-NoDerivatives 4.0 International (CC BY-NC-ND 4.0) License. 